declined to little more than a fortified village ${ }^{8}$. In Constantinople, it seems the traditions and skills of Roman craftsmen were maintained and, despite the grave decline and dereliction, a vital connection linked classical and mediaeval civilizations. For these reasons, Harrison's excavations at Saraçhane permit archaeo- logists to make assessments both of the political economies of the aristocracy in the age of Justinian, and of the obscure centuries which followed.

Richard Hodges is in the Department of Archaeology and Prehistory, University of Sheffield, Sheffield S10 2TN, UK.

\title{
Meteorites
}

\section{News from the early Solar System}

\section{David Wark}

AT the birth of the Solar System, some of the first solids to form in the solar nebula were refractory, $\mathrm{Ca}-\mathrm{Al}$-rich inclusions (CAIs) ${ }^{1}$. These white, marble-sized CAIs were incorporated and preserved in carbonaceous chondrite meteorites which ultimately brought them to Earth. They contain large numbers of micrometresized metal nuggets (see figure) which are composed of the very refractory metals Mo, W, Re, Pt, Os, Ir and Ru in approximately the same relative proportions as occur in the Sun. Fegley and Palme have shown ${ }^{2}$ that such alloys provide convincing evidence of high local temperatures of at least $1,300{ }^{\circ} \mathrm{C}$ in the solar nebula. Some CAIs also contain much larger opaque assemblages of OsRu grains, $\mathrm{NiFe}$ metal, magnetite $\left(\mathrm{Fe}_{3} \mathrm{O}_{4}\right)$ and various other phases. In contrast to the nuggets, these larger refractory-metal assemblages do not reveal much about high-temperature events. But, as Blum et al. explain on page 405 of this issue ${ }^{3}$, they provide rich information about the lower temperature, post-formation history of the CAIs.

In a series of elegant laboratory experiments, Blum et al. demonstrate that the opaque assemblages (see their figures on pages 405 and 406) formed in situ in the CAIs by the oxidation of solidified globules of $\mathrm{FeNi}$ metal containing refractory metals in solid solution. Removal of $\mathrm{Fe}$ from the metal to form magnetite eventually caused grains of the less soluble metals $\mathrm{Os}$ and $\mathrm{Ru}$ to exsolve. Although this oxidation and exsolution model $l^{4.5}$ is not new, the work of Blum et al. places for the first time quantitative constraints on the temperature $\left(600{ }^{\circ} \mathrm{C}\right)$ and oxygen partial pressure $\left(p \mathrm{O}_{2}\right.$, six orders of magnitude higher than in solar gas) at which the assemblages formed.

The other achievement of the work is that it excludes, on the basis of $\mathrm{Ru}$ diffusion profiles in the NiFe metal that surrounds the exsolved OsRu grains, models ${ }^{6}$ in which pre-existing opaque assemblages were incorporated into still molten CAIs. The impetus for such capture models came from the fact that some opaque assemblages contain highly oxidized components, such as $\mathrm{Fe}_{3} \mathrm{O}_{4}$ and $\mathrm{CaMoO}_{4}$, that are distinctly out of place among the highly reduced, $\mathrm{Ti}^{3+}$-bearing silicates of the host CAIs. The opaque assemblages were therefore named Fremdling $e^{7}$ (strangers) by El Goresy, who suggested that they might contain information about extreme nebular environments, perhaps even about pre-solar environments in supernova ejecta. Although such capture models raised hopes that we might have stumbled upon some very exotic materials, the models were never quite able to account for the survival at $1,250^{\circ} \mathrm{C}$ in the molten CAIs of the very volatile components (sulphides, Sn, Ge) that are not

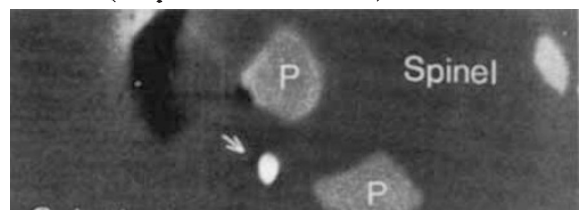

\section{Spinel}

\section{5 um}
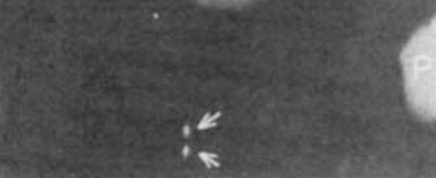

Scanning electron micrograph showing a portion of a CAI containing typical refractory-metal nuggets (arrows). P, grains of perovskite $\left(\mathrm{CaTiO}_{3}\right)$ in spinel $\left(\mathrm{MgAl}_{2} \mathrm{O}_{4}\right)$. The alloy nuggets contain (in weight per cent) $\sim 24 \mathrm{Pt}, 18$ Mo, $16 \mathrm{Ru}, 12 \mathrm{Os}, 12 \mathrm{Ir}, 11 \mathrm{Fe}, 3 \mathrm{~W}, 2 \mathrm{Ni}$ and 1 $\mathrm{Re}$. Alloys like these, in which the refractory (Mo, W, Re) and noble (Pt-group) metals are combined, do not occur naturally on Earth.

uncommon in opaque assemblages.

We may not yet have heard the last of Fremdlinge however: there is evidence that there are at least some opaque objects foreign to their host CAIs, though not in the originally intended sense of having been incorporated ready-made. This evidence was uncovered by Bischoff and Palme who extracted and analysed several large intact opaque assemblages, and found to their surprise that the bodies possessed a completely different refractory-metal signature from that of the host CAI. They suggested that a few large, homogeneous but foreign metal grains were captured by the molten CAI and while cooling, underwent oxidation and exsolution.

The experiments of Blum et al. not only reproduce the textures observed in the natural opaque assemblages, but also are able to place limits of 10 days to 10 years on the duration of the oxidaton and exsolution process, depending on the particular temperature at which exsolution began. This is probably far too short a time (the cooling is too fast) for the process to have occurred in the well-insulated planetesimals from which meteorites originate, and implies instead that the CAIs were still drifting in the nebular gas. According to the experiments, the $p \mathrm{O}$, of the gas surrounding the CAIs at this time was some six orders of magnitude higher than that of the approximately solar gas in which the host CAIs crystallized at about $1,250^{\circ} \mathrm{C}$. Because oxidation of the metal did not begin until the CAIs had cooled to about $600^{\circ} \mathrm{C}$, the $p \mathrm{O}_{2}$ of the gas probably increased only gradually as the temperature fell. There is some independent evidence for such a gradual increase in $p \mathrm{O}_{2}$. Palme and I calculate ${ }^{9}$ that oxidized $\mathrm{Fe}^{2+}$ was introduced from the nebula into the rims of CAIs and olivine chondrules at a $p \mathrm{O}_{2}$ roughly two orders of magnitude higher than solar gas at the intermediate temperature of about $900^{\circ} \mathrm{C}$.

The interesting question follows: if we are indeed seeing a trend of increasing $p \mathrm{O}_{2}$ as the nebular gas cooled, what was the cause of the increase? Was oxygen being added, perhaps in the form of $\mathrm{H}_{2} \mathrm{O}$ ice from the outer Solar System? Or, equivalently, was $\mathrm{H}_{2}$ being preferentially removed, perhaps as part of the inevitable dispersal of the nebula as the Solar System evolved? It is conventional to speculate that intense solar wind outbursts during a 'T-Tauri' phase of the early Sun were the 'broom' which swept residual gas out of the solar nebula. Even assuming that to be true, however, it is still not known how far the formation of meteorites and accretion of planetesimals had progressed when the $T$-Tauri winds are supposed to have blown. Almost nothing is known for certain about the timing of the accretion of the inner (terrestrial) planets relative to that of the outer (gaseous) planets, or relative to the thermonuclear ignition of the protoSun, nor about the duration of each process. There is no shortage of problems, and investigations of meteorites continue to provide a touchstone for theoretical modelling of the origin and evolution of the Solar System, and of the star-forming process in general.

1. Grossman, L. A. Rev. Earth planet. Sci. 8, 559-608 (1980). 2. Fegley, B. \& Palme, H. Earth planet. Sci. Lett. 72, 311 (1985). 3. Blum, J.D., et al. Nature 331, 405-409 (1987).

4. Palme, H. \& Wlotzka, F. Earth planet. Sci. Lett. 33, 45 (1976)

. Wark, D. A. \& Lovering, J.F. Lunar Sci. IX, 1214 (1978).

6. Armstrong, J.T., El Goresy, A. \& Wasserburg, G.J. Geochim. cosmochim. Acta 49, 1001-1022 (1985).

El Goresy, A., Nagel, K. \& Ramdohr, P. Proc. 9th Lunar planet. Sci. Conf. $1279-1303$ (1978).

Bischoff, A. \& Palme, H. Geochim. cosmochim. Acta $\mathbf{5 1}$ 2733-2748 (1987).

. Palme, H. \& Wark, D.A. Lunar planet. Sci. XIX (in the press).

David Wark is at the Max-Planck-Institüt für Chemie, Saarstrasse 23, Postfach 3060, D-6500 Mainz, FRG 